\title{
Effects of recombinant human growth hormone in the treatment of dwarfism and relationship between IGF-1, IGFBP-3 and thyroid hormone
}

\author{
SHANXIANG REN ${ }^{1}$, YUXIANG NIE ${ }^{2}$ and AIHONG WANG ${ }^{1}$ \\ Departments of ${ }^{1}$ Pediatrics and ${ }^{2}$ Nutrition, Dongying People's Hospital, Dongying, Shandong 257000, P.R. China
}

Received May 3, 2016; Accepted September 30, 2016

DOI: $10.3892 / \mathrm{etm} .2016 .3831$

\begin{abstract}
The effects of recombinant human growth hormone (rhGH) in the treatment of dwarfism and the relationship between insulin-like growth factor (IGF)-1, IGF-binding protein (IGFBP)-3 and thyroid hormone were examined in the present study. For this purpose, 66 patients diagnosed with dwarfism were selected retrospectively, with 36 cases of growth hormone deficiency (GHD) and 30 cases of idiopathic short stature (ISS). The therapeutic dose of GHD $0.10 \mathrm{IU} / \mathrm{kg} \cdot$ day and ISS $0.15 \mathrm{IU} / \mathrm{kg} \cdot$ day were injected subcutaneously every night before sleep until adulthood. The average follow-up was 5 years, and the results were evaluated and measured every 3 months, including height, BA, secondary test of growth hormone $(\mathrm{GH}$ peak), IGF-1, IGFBP-3 and thyroid hormone (FT3, FT4 and TSH). After treatment, the height, BA, GH peak, IGF-A and IGFBP-3 of the GHD group were all increased, and the differences were statistically significant $(\mathrm{P}<0.05)$, while FT3, FT4 and TSH had no significant change $(\mathrm{P}<0.05)$. The height and $\mathrm{BA}$ increased and the differences were statistically significant $(\mathrm{P}<0.05)$. The indexes of the ISS group were not statistically significant $(\mathrm{P}>0.05)$. The results of the Pearson-related analysis suggested that GH peak of the GHD group, IGF-1 and IGFBP-3 were positively associated with height $(\mathrm{P}<0.05)$, and had no relationship with BA $(\mathrm{P}<0.05)$. None of the above indexes of the ISS group had an obvious correlation with height and BA (P>0.05). rhGH was effective for GHD and ISS, with the GHD effect being positively associated with the GH peak, IGF-1 and IGFBP-3. ISS had no obvious relationship with GH peak, IGF-1 and IGFBP-3 although other influencing factors may be involved.
\end{abstract}

Correspondence to: Dr Shanxiang Ren, Department of Pediatrics, Dongying People's Hospital, 317 Southeast Road, Dongying, Shandong 257000, P.R. China

E-mail: ren_shanxiang1@163.com

Key words: recombinant human growth hormone, insulin-like growth factor-1, insulin-like growth factor-binding protein-3, thyroid hormone, growth hormone deficiency, idiopathic short stature, dwarfism

\section{Introduction}

Recombinant human growth hormone (rhGH) may be applied to growth hormone deficiency (GHD), gonadal dysgenesis, Noonan syndrome, SBS, chronic renal insufficiency, Prader-Willi syndrome, idiopathic short stature (ISS), SHOX gene deletion and SGA $(1,2)$. It can not only promote linear growth, but also improve body composition and metabolism, increase bone density, and improve the quality of life. Relevant instructions of various countries provide guidance for indication, application notes, adverse reaction monitoring to ensure the safety and effectiveness of the drugs (3-5).

Previous studies showed that growth hormone $(\mathrm{GH})$ secretion is similar to pulse releasing in that its excitation test cannot diagnose dwarfism and assess the therapeutic effect efficiently $(6,7)$. Previous findings showed that the effects of $\mathrm{GH}$ growth promotion mechanism, insulin-like growth factor (IGF)-1 and IGF-binding protein (IGFBP)-3 are associated with the SHOX gene $(8,9)$. Additionally, the stability of IGF-1 and IGFBP-3 in vivo may become a good index of evaluating the disease process. Thyroid hormone plays an important role in growth and metabolism and early intellectual development (10). Consequently, the present study analyzed the effects of rhGH in the treatment of dwarfism and the relationship between IGF-1, IGFBP-3 and thyroid hormone.

\section{Materials and methods}

Patients. In total, 66 patients diagnosed with dwarfism from January, 2005 to January, 2010 were selected retrospectively, of whom 36 cases were GHD and 30 cases were ISS, according to the ISS diagnosis criteria and the GH application guidelines by American Lawson-Wilkins Pediatric Endocrine Society, ESPE, GHRS and AACE (3-5). The initial therapeutic dose GHD $0.10 \mathrm{IU} / \mathrm{kg} \cdot$ day and ISS $0.15 \mathrm{IU} / \mathrm{kg} \cdot$ day were injected subcutaneously every night before sleep until adulthood. The dose was adjusted according to the therapeutic effect and evaluation index. When the height reached the normal adult height range ( $>-2 \mathrm{SD})$, or next to the normal height, i.e., growth rate $<2 \mathrm{~cm} /$ year, boy's BA $>16$ years, girl's BA $>14$ years, the drugs were stopped. The drugs were also used until 6-7 years after reaching adult height. Congenital dysplasia, chromosomal abnormalities, nutritional disorders, and imperfect clinical data lost to follow-up were all excluded. The study was 
Table I. Comparison of observation index among the two groups of children.

\begin{tabular}{|c|c|c|c|c|c|c|c|c|}
\hline \multirow[b]{2}{*}{$\begin{array}{l}\text { Observation } \\
\text { index }\end{array}$} & \multicolumn{4}{|c|}{ GHD group } & \multicolumn{4}{|c|}{ ISS group } \\
\hline & $\begin{array}{l}\text { Before } \\
\text { treatment }\end{array}$ & $\begin{array}{c}5 \text { years } \\
\text { follow-up }\end{array}$ & t-test & P-value & $\begin{array}{l}\text { Before } \\
\text { treatment }\end{array}$ & $\begin{array}{l}5 \text { years } \\
\text { follow-up }\end{array}$ & $\mathrm{t}$-test & P-value \\
\hline Height $(\mathrm{cm})$ & $106.0 \pm 2.5$ & $142.6 \pm 3.3$ & 23.624 & $<0.001$ & $103.2 \pm 2.4^{\mathrm{a}}$ & $139.8 \pm 3.5^{\mathrm{a}}$ & 20.513 & $<0.001$ \\
\hline BA (years) & $5.0 \pm 1.3$ & $9.4 \pm 1.6$ & 12.625 & $<0.001$ & $4.9 \pm 1.4^{\mathrm{a}}$ & $9.2 \pm 1.5^{\mathrm{a}}$ & 11.528 & $<0.001$ \\
\hline GH peak $(\mathrm{ng} / \mathrm{ml})$ & $5.6 \pm 1.3$ & $7.7 \pm 1.6$ & 6.625 & 0.022 & $12.4 \pm 3.3^{b}$ & $12.5 \pm 3.2^{\mathrm{b}}$ & 0.724 & 0.532 \\
\hline IGF-1 (ng/ml) & $156.2 \pm 72.7$ & $325.2 \pm 93.3$ & 35.212 & $<0.001$ & $284.5 \pm 69.2^{\mathrm{b}}$ & $312.4 \pm 72.1^{\mathrm{a}}$ & 1.230 & 0.965 \\
\hline IGFBP-3 $(\mu \mathrm{g} / \mathrm{ml})$ & $3.0 \pm 1.1$ & $3.8 \pm 1.2$ & 7.541 & 0.013 & $3.5 \pm 1.4^{\mathrm{b}}$ & $3.6 \pm 1.2^{\mathrm{a}}$ & 0.636 & 0.825 \\
\hline FT3 (pmol/l) & $5.2 \pm 1.3$ & $5.3 \pm 1.4$ & 0.628 & 0.426 & $5.1 \pm 1.2^{\mathrm{a}}$ & $5.0 \pm 1.1^{\mathrm{a}}$ & 0.323 & 0.421 \\
\hline FT4 (pmol/l) & $16.2 \pm 2.5$ & $16.5 \pm 2.4$ & 0.936 & 0.864 & $16.3 \pm 2.3^{\mathrm{a}}$ & $16.4 \pm 2.5^{\mathrm{a}}$ & 0.627 & 0.539 \\
\hline $\mathrm{TSH}(\mu \mathrm{IU} / \mathrm{ml})$ & $3.2 \pm 0.8$ & $3.1 \pm 0.7$ & 0.328 & 0.427 & $3.2 \pm 0.6^{\mathrm{a}}$ & $3.3 \pm 0.5^{\mathrm{a}}$ & 0.392 & 0.214 \\
\hline
\end{tabular}

${ }^{\mathrm{a} C}$ Comparison of ISS group and GHD group P $>0.05$; ${ }^{\mathrm{b}}$ comparison of ISS group and GHD group $\mathrm{P}<0.05$. GHD, growth hormone deficiency; ISS, idiopathic short stature; GH, growth hormone; IGF-1, insulin-like growth factor-1; IGFBP-3, insulin-like growth factor-binding protein-3.

approved by the Ethics Committee of the Dongying People's Hospital (Shandong, China). All of the families of the patients were informed of the aims of the study and the parents gave informed consent. The GHD group included 20 boys and 16 girls; aged 2-10 years, with an average of 6.6 22.4 years. The ISS group included 16 boys and 14 girls; aged 2.5-13 years, with an average of $6.9 \pm 2.5$ years. The differences of gender and age of the two groups were not statistically significant $(\mathrm{P}>0.05)$.

Observation index. The patients were followed up until January 2016, with an average follow-up of $\sim 5$ years; the effects and indexes, including height, BA, secondary test of growth hormone (GH peak), IGF-1, IGFBP-3 and thyroid hormone (FT3, FT4 and TSH) were evaluated every 3 months. The height was measured by a specially assigned individual with the same tool (produced by Shanghai Nine Peaks Weighing Apparatus Factory, Shanghai, China). The under collars were fixed, heels, buttocks, occiputs touched the column at the same time, and the average value was taken after 3 continuous measurements, with centimeters as the unit. The BA was measured by taking X-ray of the left hand, including the hand bone, wrist and radial ulnar stem $3-4 \mathrm{~cm}$. The same specially assigned investigator scanned the image and evaluated the BA according to the Chinese bone maturation evaluation standard scoring method. Growth hormone stimulation test included: Pyridostigmine bromide ( $4 \mathrm{mg} / \mathrm{kg}$, max $60 \mathrm{mg}$ ) and clonidine $(2.5 \mu \mathrm{g} / \mathrm{kg}$, max $150 \mu \mathrm{g})$ taken orally on an empty stomach. Subsequently, $3 \mathrm{ml}$ of median elbow vein blood was drawn 0, 60, 90 and 120 min after taking the drugs. The serum GH level was measured with the Siemens automated Immulite 2000 chemiluminescence detection instrument (Siemens Healthcare Diagnostics, Los Angeles, CA, USA) and the original kit; IGF-1 and IGFBP-3 were measured with the double antibody sandwich method and the kits were provided by Sigma-Aldrich (St. Louis, MO, USA). FT3, FT4 and TSH were measured using the radio immunity method, the kits were provided by China Institute of Atomic Energy (Beijing, China), and the measuring tool was SN-682 $\gamma$-calculating instrument produced by Shanghai Institute of Atomic Energy (Shanghai, China).

Adverse reactions such as retention of water and sodium (eyelid and facial edema, arthritis and carpal tunnel syndrome), impaired glucose tolerance, benign intracranial hypertension, hypothyroidism, slipped capital femoral epiphysis, scoliosis, pigmented nevus, adenoid hypertrophy, hands and feet become, local swelling and rash, otitis media and male mammary gland development, and tumors were all under detection.

Statistical analysis. SPSS 19.0 statistical software (Chicago, IL, USA) was used for statistical input and analysis, and data were expressed as mean \pm standard deviation. Comparisons within the group were made by the paired t-test, comparisons between groups were made by the independent sample t-test, and comparisons of different time-points were made by repeated measure variance. Qualitative data were expressed as cases or percentage (\%), and comparisons between groups were made using $\chi^{2}$ test. Quantitative data were analyzed using Pearson. $\mathrm{P}<0.05$ was statistically significant.

\section{Results}

Comparison of the observation index among the two groups of children. For children in the GHD group, their height, BA, GH peak, IGF-1 and IGFBP-3 all increased after treatment, and the differences were statistically significant $(\mathrm{P}<0.05)$, but no obvious change in FT3, FT4 and TSH was observed/obtained $(\mathrm{P}>0.05)$. For children In the ISS group, their height and BA increased after treatment, but no obvious change in other indexes. There was no obvious change in the height, BA, FT3, FT4 or TSH of the ISS group and GHD group before and after treatment, GH peaks of the ISS group before and after treatment were higher than those of the GHD group; before treatment, IGF-1 and IGFBP-3 were higher than those of the GHD group, but no difference after treatment (Table I).

Comparison of GH peak, IGF-1 and IGFBP-3 of the two groups at different time-points. Comparison of GH peak, 


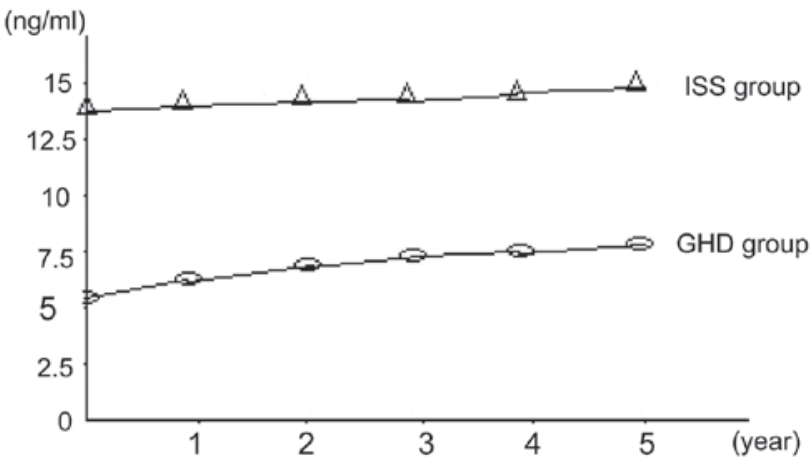

Figure 1. Variation trend of GH peak at different follow-up times. GH, growth hormone.

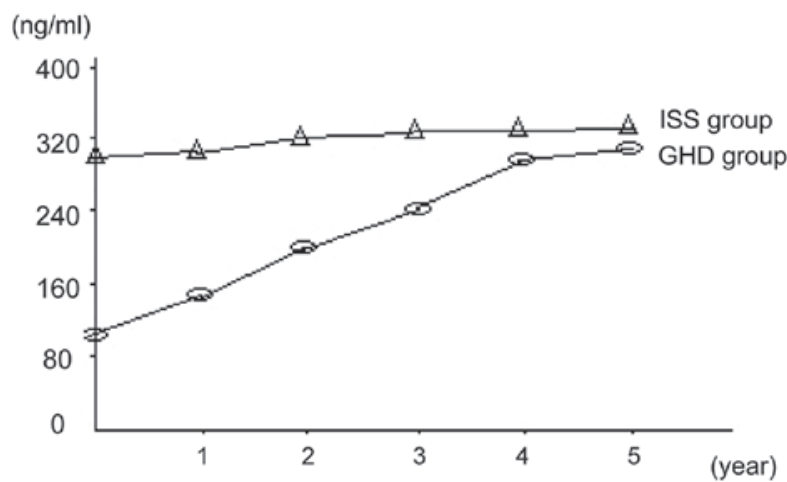

Figure 2. Variation trend of IGF-1 at different follow-up times. IGF-1, insulin-like growth factor-1.

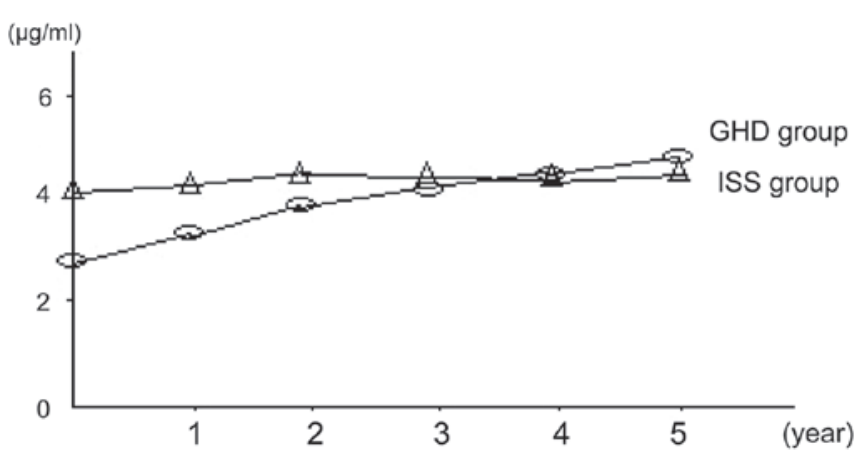

Figure 3. Variation trend of IGFBP-3 at different follow-up times. IGFBP-3, insulin-like growth factor-binding protein-3.

IGF-1 and IGFBP-3 of the GHD group at different time-points suggested that the differences were statistically significant $(\mathrm{P}<0.05)$. A comparison of the ISS group suggested the differences were not statistically significant (Figs. 1-3).

Relevant analysis. Analysis on the relationship between the GH peak, IGF-1, IGFBP-3, FT3, FT4, TSH and height and BA was made, and the results showed that, the GH peak, IGF-1, IGFBP-3 of the GHD group was positively correlated with height $(r=0.326, P=0.030 ; r=0.357, P=0.026 ; r=0.040$, $\mathrm{P}=0.022)$, but was not associated with $\mathrm{BA}(\mathrm{P}<0.05)$. The above indexes of the ISS group had no obvious relationship with height and $\mathrm{BA}(\mathrm{P}<0.05)$.

\section{Discussion}

The innovation of the present study was that it compared separately the effects of rhGH on the height and BA of the GHD children and the ISS children. It also analyzed the variation trends of GH peak, IGF-1, IGFBP-3, FT3, FT4 and TSH. The average follow-up lasted for 5 years, in the course of which no obvious complication was found and the drug was used continually after symptomatic treatment, which showed that proper dose of rhGH was safe. At the same time, the medication time was long, and $90 \%$ of the children continued to use the drug after the follow-up observation.

The study showed that, for children in the GHD group, their height, BA, GH peak, IGF-1 and IGFBP-3 all increased after treatment, and the differences were statistically significant $(\mathrm{P}<0.05)$, but no obvious change was observed in FT3, FT4 and TSH $(\mathrm{P}>0.05)$. For children belonging to the ISS group, their height and BA increased after treatment, but no obvious change was observed in other indexes. There was no obvious change in the height, BA, FT3, FT4 or TSH of the ISS and GHD groups before or after treatment. The GH peaks of the ISS group before and after treatment were higher than those of the GHD group, where before treatment, IGF-1 and IGFBP-3 were higher than those of the GHD group, but no difference was observed after treatment. rhGH may act on GHD and ISS by promoting linear growth and bone growth. It was previously shown that rhGH had a good effect on ISS by promoting linear growth, and GH-IGH-1 axis played an important role $(11,12)$. GH promoted tissues outside the skeletal system, especially the liver to produce IGF-1, which entered the target organs to exert the endocrine function, thus mediating the growth-promoting effect of GH $(13,14)$. GH had s direct influence on the target cells as it could promote the differentiation of the anterior chondrocytes into chondrocytes, stimulate synthesis and secretion of IGF-1 in certain parts of the body. Furthermore, IGF-1 could promote the chondrocyte proliferation in an autocrine and paracrine manner and stimulate the liver to produce IGF-1 and IGFBP-3, IGFBP-3 in circulation, which regulated the biological availability of IGF-1 in the target cells (15). However, previous studies showed that the BA maturity promotion effect of rhGH was limited $(16,17)$. The reason may be concerned with the time of treatment and follow-up; however, the specific mechanism remains to be further analyzed. ISS is a diagnosis of exclusion, i.e., it is in reality a combination of a group of unknown dwarfisms. With the development of the gene detection technique, more ISS children were found to be defected in hypothalamuspituitary insulin-like growth factor axis function, which may be one of the effective theories of treating ISS with rhGH (18). At the same time, it was identified that the GH peak, IGF-1 and IGFBP-3 had no significant change before and after treatment. Therefore it was considered that GH-IGF-1 axis may not play a major role in the pathogenesis. The study also found that the ISS children may suffer a defect of growth hormone because the protein binding level of their serum GH decreased (19). Mutation or abnormal signal transmission of the GH receptor may cause part insensitivity of GH and the gene-like SHOX was also reported to have the same effect.

A comparison of the GH peak, IGF-1 and IGFBP-3 of the GHD group at different time points suggested the differences 
were statistically significant. The Pearson relevant analysis revealed that the GH peak, IGF-1 and IGFBP-3 of the GHD group were positively correlated with height, while no relationship with BA was identified. The above indexes of the ISS group had no obvious relationship with height or BA. It was suggested that the height promotion effect of rhGH treatment was related to GH peak, IGF-1 and IGFBP-3. Thus, regular monitoring rhGH may be useful in the treatment effect evaluation. In conclusion, rhGH was effective for GHD and ISS, and the GHD effect was positively associated with the GH peak, IGF-1 and IGFBP-3. ISS had no obvious relationship with the GH peak, IGF-1 and IGFBP-3; however, other influencing factors may be involved.

\section{References}

1. Iglesias P and Díez JJ: Clinical applications of recombinant human growth hormone in adults. Expert Opin Pharmacother 1: 97-107, 1999.

2. Sassolas G: Potential therapeutic applications of growth hormone in adults. Horm Res 42: 72-78, 1994.

3. Wilson TA, Rose SR, Cohen P, Rogol AD, Backeljauw P, Brown R, Hardin DS, Kemp SF, Lawson M, Radovick S, et al Lawson Wilkins Pediatric Endocrinology Society Drug and Therapeutics Committee: Update of guidelines for the use of growth hormone in children: The Lawson Wilkins Pediatric Endocrinology Society Drug and Therapeutics Committee. J Pediatr 143: 415-421, 2003.

4. Growth Hormone Research Society; GH Research Society: Consensus guidelines for the diagnosis and treatment of growth hormone $(\mathrm{GH})$ deficiency in childhood and adolescence: summary statement of the GH Research Society. J Clin Endocrinol Metab 85: 3990-3993, 2000.

5. Gharib H, Cook DM, Saenger PH, Bengtsson BA, Feld S, Nippoldt TB, Rodbard HW, Seibel JA, Vance ML and Zimmerman D; American Association of Clinical Endocrinologists Growth Hormone Task Force: American Association of Clinical Endocrinologists medical guidelines for clinical practice for growth hormone use in adults and children - 2003 update. Endocr Pract 9: 64-76, 2003.

6. Teran E, Chesner J and Rapaport R: Growth and growth hormone: an overview. Growth Horm IGF Res 28: 3-5, 2016.

7. Albertsson-Wikland K: Growth hormone therapy needs to be tailored based on individual responsiveness in children with idiopathic short stature. J Pediatr 159: 516, 2011.

8. Liu Z, Mohan S and Yakar S: Does the GH/IGF-1 axis contribute to skeletal sexual dimorphism? Evidence from mouse studies. Growth Horm IGF Res 27: 7-17, 2016.
9. Hawkes CP and Grimberg A: Insulin-like growth factor-I is a marker for the nutritional state. Pediatr Endocrinol Rev 13: 499-511, 2015.

10. Gaspari L, Paris F, Leboucq N, Bonafé A and Sultan C: Reversible growth failure and complete $\mathrm{GH}$ deficiency in a 4-year-old girl with very early Hashimoto's thyroiditis and subsequent hyperplasia of pituitary thyrotroph cells. Eur J Pediat: Feb 2, 2016 (Epub ahead of print).

11. Inzaghi $\mathrm{E}$ and Cianfarani S: The challenge of growth hormone deficiency diagnosis and treatment during the transition from puberty into adulthood. Front Endocrinol (Lausanne) 4: 34, 2013.

12. Cook DM, Yuen KC, Biller BM, Kemp SF and Vance ML; American Association of Clinical Endocrinologists: American Association of Clinical Endocrinologists medical guidelines for clinical practice for growth hormone use in growth hormone-deficient adults and transition patients - 2009 update: executive summary of recommendations. Endocr Pract 15: 580-586, 2009.

13. Ho KK; 2007 GH Deficiency Consensus Workshop Participants: Consensus guidelines for the diagnosis and treatment of adults with GH deficiency II: a statement of the GH Research Society in association with the European Society for Pediatric Endocrinology, Lawson Wilkins Society, European Society of Endocrinology, Japan Endocrine Society, and Endocrine Society of Australia. Eur J Endocrinol 157: 695-700, 2007.

14. Molitch ME, Clemmons DR, Malozowski S, Merriam GR and Vance ML; Endocrine Society: Evaluation and treatment of adult growth hormone deficiency: an Endocrine Society clinical practice guideline. J Clin Endocrinol Metab 96: 1587-1609, 2011.

15. Clayton PE, Cuneo RC, Juul A, Monson JP, Shalet SM and Tauber M; European Society of Paediatric Endocrinology: Consensus statement on the management of the GH-treated adolescent in the transition to adult care. Eur J Endocrinol 152: 165-170, 2005.

16. Bell J, Parker KL, Swinford RD, Hoffman AR, Maneatis T and Lippe B: Long-term safety of recombinant human growth hormone in children. J Clin Endocrinol Metab 95: 167-177, 2010.

17. Tritos NA and Klibanski A: Effects of growth hormone on bone. Prog Mol Biol Transl Sci 138: 193-211, 2016.

18. Cohen P, Rogol AD, Deal CL, Saenger P, Reiter EO, Ross JL, Chernausek SD, Savage MO and Wit JM; 2007 ISS Consensus Workshop participants: Consensus statement on the diagnosis and treatment of children with idiopathic short stature: a summary of the Growth Hormone Research Society, the Lawson Wilkins Pediatric Endocrine Society, and the European Society for Paediatric Endocrinology Workshop. J Clin Endocrinol Metab 93: 4210-4217, 2008

19. Salerno M, Balestrieri B, Matrecano E, Officioso A Rosenfeld RG, Di Maio S, Fimiani G, Ursini MV and Pignata C: Abnormal GH receptor signaling in children with idiopathic short stature. J Clin Endocrinol Metab 86: 3882-3888, 2001. 